\title{
Head and Neck Cancer cN3b TNM Finding v8
}

National Cancer Institute

\section{Source}

National Cancer Institute. Head and Neck Cancer cN3b TNM Finding v8. NCI Thesaurus.

Code C132641.

Head and neck cancer with metastasis in a single ipsilateral lymph node ENE(+); or metastases in multiple ipsilateral, contralateral, or bilateral lymph nodes, any with ENE(+). (from AJCC 8th Ed.) 